GONÇALVES, Marco Antonio. 2008. 0 real imaginado: etnografia, cinema e surrealismo em Jean Rouch. Rio de Janeiro: Topbooks. 239 pp.

\title{
Eliska Altmann
}

Professora adjunta do departamento de Letras e Ciências Sociais da UFRRJ

"Por que não?" parece uma boa pergunta introdutória para uma série de indagações despertadas a partir da leitura do livro O real imaginado: etnografia, cinema e surrealismo em Jean Rouch, de Marco Antonio Gonçalves. Homônimo do navio (em francês, "Pourquoi pas?") navegado no início do século passado pelo pai explorador do futuro antropólogo-cineasta, a interrogação parece não servir somente à obra de Jean Rouch, mas ao fazer antropológico-cinematográfico em geral. Nesse sentido, outras indagações se seguiriam. Por que não fazer antropologia por intermédio de imagens? Por que não inventar o outro como sujeito em vez de objeto? Por que não colocar o antropólogo na posição do observado, invertendo certas posturas colonialistas da disciplina? Por que não questionar a cientificidade e a verdade antropológicas? Por que não buscar o outro em si próprio? Por que não inverter, interagir, ou mesmo hibridizar alteridades, como as do nativo e do antropólogo? Por que não tomar o real no nível da fabulação, 
ou melhor, do surreal? Enfim, por que não extrair e construir "verdades" de "ficções" e vice-versa?

Sem querer trazer respostas definitivas a essas e outras questões, Marco Antonio disseca três dos 107 filmes realizados por Jean Rouch entre 1947 e 2002. O recorte em Os mestres loucos (1954), Eu, um negro (1958) e Jaguar (1954, finalizado em 1967), que compõem a "trilogia migratória" do antropólogo-cineasta, dá-se pelo fato de "os três filmes terem como foco os nativos do Níger que experimentam a migração, seja na Costa do Ouro, atual Gana, seja na Costa do Marfim. Foram filmados com a mesma câmera, a velha Bell \& Howell 16mm que restringia a duração dos planos (não alcançavam mais do que 25 segundos) e a captação do som, que necessitava ser obtida através de uma pós-produção", explica o autor (:27). Indo mais além, nota-se que há uma ambiguidade insinuada nos três títulos a tratar, também, de outras espécies de migração (ou reinvenção de si): a do próprio Jean Rouch na África com seus sujeitosobjetos; a do filme etnográfico e seus fatos sociais mimetizados; e, finalmente, a da antropologia anticolonialista e sua produção de verdades aparentes. É imperativo atentar, ainda, a importância da narração nos filmes que, como ferramenta para contornar problemas de sincronia entre som e imagem, acaba por criar uma linguagem que torna indiscerníveis fronteiras entre documentário e ficção.

De fato, de toda a obra de Jean Rouch, poucos filmes foram realizados fora da África, como o clássico do cinema-verdade Chronique d'un été (1960), filmado em sua Paris natal. Nas experimentações sobre etnografia imagética realizadas naquele continente, institui-se a denominada "antropologia compartilhada", na qual o antropólogo literalmente põe-se em interação com o nativo - o outro - a ponto de desconstruir ideias de autoridade etnográfica em função de uma intersubjetividade. Deste modo, Jean Rouch acaba por "autoconstruir" um personagem de si juntamente com a construção de outros personagens, criando sua "etnoficção". O que se privilegia aqui é "a verdade do cinema e não a verdade no cinema", explica o cineasta. Em outras palavras, são dois os pontos a compor o método fílmico-etnográfico rouchiano, assim como sua ética. O primeiro é o que trata de fazer do objeto sujeito, ponto-chave da antropologia compartilhada. O entrecruzamento proposto nessa perspectiva dessubjetiva o antropólogo em função de uma outra forma de subjetivação, a saber, a ressubjetivação da outridade. O que se questiona, no caso, é a hierarquização estabelecida por certa antropologia. O segundo ponto encontrase no compromisso dessa antropologia compartilhada em mudar o foco de uma suposta verdade ou de um conhecimento científico inquestionável para uma verdade fílmica, que compreende um sentido de provisoriedade, ou seja, da construção de uma verdade que se busca interpretar. A concepção de verdade, nesse sentido, está em sua possibilidade de construção a partir do que é filmado, do que é provocado pela câmera. Valoriza-se, portanto, a construção de uma verdade fílmica, e não seu estado bruto. Esse mesmo método serviria à etnografia.

Isso posto, "Filme-ritual e etnografia surrealista: os mestres loucos de Jean Rouch", primeiro capítulo do livro, propõe, a partir da recepção europeia, acadêmica e africana de Les maîtres fous, um debate sobre a alteridade referente às relações nós/outros, nativo/antropólogo. Mais do que isso, sugere-se a possibilidade de um "devir-outro" concernente ao encontro de duas entidades que não chegam a se tornar uma especular da outra, refletindo um princípio construtivo e criativo da mímesis em detrimento da mera imitação. 
Verifica-se, primeiramente, o não controle em relação às imagens produzidas a partir de sua polêmica e controversa recepção, motivada, sobretudo, pela própria ambiguidade fílmica. Afinal, o ritual "selvagem" dos hauka representaria que sociedade: a africana, a dos britânicos, ou as duas ao mesmo tempo? Quem seriam os "mestres loucos"? A partir da constatação de que o filme é uma "ritualização de um ritual", analisa-se o sentido éticoestético rouchiano, ancorado no método da antropologia compartilhada e de seu cinéma vérité. $\mathrm{O}$ "surrealismo" dessa estética ritual estaria na desestabilização dos pares opostos realidade/ficção, objetividade/subjetividade provocada pelo descompasso entre imagem e som, ritual e narração, universo imagético do ritual e densidade etnográfica textual. Longe de ser meramente técnica e descritiva, a narração (ou os comentários) de Jean Rouch sobre o ritual filmado implica um significado emocional, que, subjetivo, acaba por destituir qualquer objetividade proposta por parâmetros científicos. Tal descentramento - ilustrado pela "beleza violenta" da irracional devoração do cachorro narrada racionalmente pelo antropólogo-cineasta - parece compreender a estética surrealista geradora, justamente, daquela recepção polêmica.

Sob o título "Ficção, imaginação e etnografia: a propósito de $E$ u, um negro", o segundo capítulo aprofunda concepções sobre verdade e ficção no filme etnográfico/documentário. A partir de uma análise de planos de Moi, un noir pautada, sobretudo, nas falas dos personagens, Marco Antonio examina a ambiguidade fílmica como reflexo da ambiguidade da realidade. Entendemos, então, a importância dada às falas, gravadas posteriormente ao registro das imagens. A reconstituição narrativa dos comentários e diálogos possibilita à palavra imaginada a criação de verdades, ou seja, o mundo imaginado do outro é construído por suas próprias palavras, que desvelam verdades próprias (ou essenciais). Nesse caso, na medida em que Oumarou Ganda se narra como Edward G. Robinson, ele atualiza verdades imaginadas "comme si" fosse outro. Logo, o que se expressa é uma potencialidade do falso inscrita na sinceridade, que está acima e além da realidade ou da ficção. Aqui percebemos não apenas uma condição do fazer fílmico, mas também do fazer etnográfico, uma vez que as verdades da etnografia e do filme são construídas a partir de palavras ditas pelo outro em relação com o cineasta-antropólogo. Acontece, assim, uma fusão entre etnografia e cinema, ambos construídos por imaginações e produtores de representações de outros em si próprios. $\mathrm{Na}$ medida em que "aponta para a dimensão do vivido, da experiência que se transmuta em imaginação de uma relação vivida" (:119), a sinceridade torna-se princípio da percepção surrealista a pregar uma libertação tanto da arte quanto da vida, uma realidade manifestada por meio da imaginação. O risco que o antropólogocineasta pode experimentar orientado por tal método é o de sua "etnoficção" (proposta ainda na década de 20 por Robert Flaherty) comportar um híbrido que não satisfaça o rigor científico da antropologia nem o cinema propriamente dito. Vale atentar, contudo, o entendimento de que a verdade encenada engendra um "deviroutro" a centrar um "perspectivismo" fundado num faz-de-conta. Faz-se de conta, portanto, que o cinema é verdade, que o real é ficção, que o branco é negro, que o negro é branco, que "eu é outro".

"Jaguar: etnobiografia ou 'cinema etnográfico em primeira pessoa", terceiro e último capítulo, discute mais detidamente o exercício da narração em Jean Rouch motor da simulação de si, da complexificação da alteridade e da falsificação do vivido. Jaguar, que conta a viagem de três 
amigos do Níger para a Costa do Ouro, representa a experiência de ser outro não somente quando se está em outro lugar, mas em seu recontar. Representando-se na condição de um jaguar - que, além do carro inglês, simboliza, no contexto colonial britânico, o homem moderno, sedutor, na moda e urbano - Damouré reconta esse "devir-outro". Filmado em 1954, mesmo ano em que Os mestres loucos foi rodado, Jaguar foi finalizado 13 anos depois. Assim sendo, o recontar da aventura migratória acaba por pressupor um deslocamento no tempo, quando o outro já é mesmo outro, mas se faz revivido em sua memória fabuladora. De fato, a narração gravada em 1957, improvisada em cima das imagens - e abrindo caminho para a realização de Eu, um negro -, evidencia a dialética do cinema-verdade rouchiano: a da verdade da encenação e vice-versa. Princípio nietzschiano de desvelar a essência por meio da aparência, ou deleuziano da falsificação potencializada, tal dialética suspende qualquer julgamento sobre o eu, o outro e o real. Da perspectiva do migrante, a narração pode ser entendida como tradução no sentido de uma nova autointerpretação sobre a vivência em realidade adversa. Damouré, Illo e Lam experimentam a migração sazonal nigeriana, que implica necessariamente retorno a casa, ao originário. Eles experimentam, portanto, um "quase tornar-se outro no estrangeiro" (:184). O processo de aventurar-se no desconhecido, que origina uma "ex-centricidade" do eu (e do outro), é utilizado por Jean Rouch não somente em seu cinema, sem roteiro prévio, mas em sua antropologia e etnografia, ambas pautadas em encontros que geram interpretações e consequentes "invenções de si". Aqui, uma vez mais, a verdade nada tem de objetiva, sendo olhada e construída pela objetiva da câmera, capaz de ver o que os olhos não veem - homenagem ao kino-pravda de Dziga Vertov.
Ao reescrever essas experiências, Marco Antonio estabelece uma espécie de "etnodiálogo" com Jean Rouch, seus personagens e etnografias fílmicas, trazendo à luz uma narrativa que busca traduzir problemáticas essenciais da antropologia para aqueles que pretendem pensá-la e representá-la de forma criativa. 